\begin{tabular}{|l|l|l||}
\hline \multicolumn{2}{|c|}{ PublisherInfo } \\
\hline \hline PublisherName & $:$ & BioMed Central \\
\hline \hline PublisherLocation & $:$ & London \\
\hline \hline PublisherImprintName & $:$ & BioMed Central \\
\hline \hline
\end{tabular}

\title{
Cholera virulence gene expression
}

\begin{tabular}{|l|l|l||}
\hline \multicolumn{2}{|c|}{ ArticleInfo } \\
\hline \hline ArticleID & $:$ & 3570 \\
\hline \hline ArticleDOI & $:$ & $10.1186 /$ gb-2000-1-1-reports036 \\
\hline \hline ArticleCitationID & $:$ & reports036 \\
\hline \hline ArticleSequenceNumber & $:$ & 61 \\
\hline \hline ArticleCategory & $:$ & Paper report \\
\hline \hline ArticleFirstPage & $:$ & 1 \\
\hline \hline ArticleLastPage & $:$ & 4 \\
\hline \hline & & RegistrationDate : 2000-2-23 \\
\hline ArticleHistory & $:$ & Received \\
& $:$ 2000-2-23 \\
\hline \hline ArticleCopyright & $:$ & BioMed Central Ltd2000 \\
\hline \hline ArticleGrants & $:$ & \\
\hline \hline ArticleContext & $:$ & 130591111 \\
\hline \hline
\end{tabular}




\section{Abstract}

Expression patterns of Vibrio cholerae virulence genes determined during an infection differ dramatically from those observed in conventional in vitro analyses.

\section{Significance and context}

Two key virulence genes of the bacterial pathogen Vibrio cholerae, the causative agent of cholera, encode the cholera toxin (CT) and the toxin-coregulated pilus (TCP). When internalized into the epithelial cells of the small intestine, CT causes the watery diarrhea symptomatic of cholera. TCP is a pilus essential for intestinal colonization. The regulation of $V$. cholerae virulence genes has previously been studied only in vitro, because of methodological limitations. This is not particularly satisfactory, as laboratory conditions that facilitate maximum expression of TCP and CT are unlike the conditions in the intestines of an infected animal, and when in vivo conditions are replicated, in vitro virulence gene expression is actually repressed. Furthermore, the virulence genes of the El Tor biotype of $V$. cholerae, which is responsible for the current global pandemic, are difficult to induce in vitro. Using genetically engineered bacteria containing recombinase reporter constructs of the two virulence genes, Lee et al. have now determined the temporal course of expression of these two genes in the El Tor biotype, both in vivo, during an infection in the mouse, and in vitro.

\section{Key results}

Recombinase reporter constructs were created with the $V$. cholerae tcp $A$ gene (encoding TCP) and the $c t x A$ gene (encoding CT subunit A). When induced by activation of the virulence gene promoter, the recombinase causes the excision of a selectable gene cassette from the bacterial genome. This event is stable and heritable; thus bacteria can be recovered from infected tissues at various stages and assayed for the excision event. Bacteria were removed at various stages of the infection and a temporal expression profile was built up for each gene. In some experiments, bacteria mutated for key virulence regulatory genes were used as 'background' hosts for the constructs in order to evaluate the regulation of tcp $A$ and $c t x A$. The tcp $A$ gene was induced biphasically in vivo. Although slight induction of $c t x A$ expression was observed after the first $t c p A$ expression phase, maximum expression of $c t x A$ was only observed during the second phase of $t c p A$ expression. Induction of $c t x A$ required expression of $t c p A$. This necessity for $t c p A$ expression was not observed under in vitro conditions, nor is the biphasic 
expression of $t c p A$ seen in vitro. The expression patterns of $t c p A$ and $\operatorname{ctx} A$ within the mutant backgrounds were also found to differ during an infection from their expression in vitro.

\section{Methodological innovations}

Lee et al. used a modification of the recombinase-based in vivo expression technology (RIVET). Although this is a very powerful method for monitoring patterns of gene expression in vivo, it is critical that the background expression of the gene under study is minimal, in order to allow construction of the recombinant strain. Both $t c p A$ and $\operatorname{ctx} A$ have high basal levels of expression, which initially prevented their study by this method. The authors overcame this problem by mutating the ribosome-binding site of the recombinase reporter in such a way as to suppress the initiation of translation. A variety of recombinase mutants were created with differing translation levels which could be matched to any given gene with background expression, thus creating a 'tunable' RIVET.

\section{Links}

The Camilli lab homepage provides contact details and more information on the group's research.

\section{Conclusions}

On the basis of the results in vivo, a new model for the regulation and expression of TCP and CT during an infection is presented. The authors draw particular attention to the two induction events for $t c p A$, with the possibility of a quorum-sensing system for the second. The initial expression of tcp $A$ could be caused by bacterial regulatory proteins sensing a host signal in the upper regions of the gut. Synthesis of TcpA could allow $V$. cholerae cells to attach to the epithelium of the small intestine and remain there. Later, the second (maximal) induction event occurs amongst these cells retained in the small intestine. Given the proximity of the bacteria to the epithelium, this could be a host-derived signal. Alternatively, a bacterial signal could be the cue. One possibility would be a quorum-dependent signal, one dependent on the number of bacteria. The authors suggest that maximal expression of CT is dependent on prior colonization of the intestinal epithelial surface and that TCP is crucial for this.

\section{Reporter's comments}


The importance of assessing gene expression in bacterial pathogens in vivo and not just in vitro is clearly demonstrated by this paper. Furthermore, the 'tunable' RIVET technology should be applicable to many other experimental systems.

\section{Table of links}

Cell

Camilli lab

\section{References}

1. Lee SH, Hava DL, Waldor MK, Camilli A: Regulation and temporal expression patterns of Vibrio cholerae virulence genes during infection. Cell. 1999, 99: 625-634. 0092-1903 